\title{
A New Fluctuation Index: Characteristics and Application to Hydro-Wind Systems
}

\author{
Xianxun Wang ${ }^{1,2}$, Yadong Mei ${ }^{1,2, *}$, Hao Cai ${ }^{1,2}$ and Xiangyu Cong ${ }^{3}$ \\ 1 State Key Laboratory of Water Resource and Hydropower Engineering Science, Wuhan University, \\ Wuhan 430072, Hubei, China; wangxianxun@whu.edu.cn (X.W.); haocai@whu.edu.cn (H.C.) \\ 2 Hubei Collaborative Innovation Center for Water Resources Security, Wuhan 430072, Hubei, China \\ 3 POWERCHINA Kunming Engineering Corporation Limited, Kunming 650051, Yunnan, China; \\ cong_xy@khidi.com \\ * Correspondence: ydmei@whu.edu.cn; Tel.: +86-27-6877-4452; Fax: +86-27-6877-2310
}

Academic Editor: Ånund Killingtveit

Received: 25 November 2015; Accepted: 25 January 2016; Published: 18 February 2016

\begin{abstract}
Hydro-wind system output fluctuations are the primary factors used to assess the effects of hydropower on power companies compensating for wind power intermittency. Considering that most fluctuation indices can only characterize one aspect of fluctuations, namely, the quantitative or contour variations, we present a new index that uses the standard deviation (SD) and rotation angle to detect the quantitative variations and contour changes, respectively. Herein, the new index is compared with commonly used indices, specifically, the first-order difference, SD, and Richards-Baker flashiness indices. The results of tests performed using various processes and disposals show that: (1) when dealing with the process by moving average, repeating or overlay disposal, the new index performs comparably to the other indices, while when dealing with the process by zooming disposal, it more fully describes the fluctuation characteristics by taking both quantitative and contour variations into consideration; (2) when the new index is used to characterize the hydro-wind output fluctuations with different resources and capacities, the outcomes coincide with the mechanisms of hydro-wind systems. This study presents a new way to characterize the fluctuation of hydro-wind output.
\end{abstract}

Keywords: fluctuation characterization; hydro-wind output; standard deviation; rotation angle

\section{Introduction}

With the rapid growth of wind power use in recent years, the power grid faces challenges in terms of reliability and economic operability due to the stochastic nature and intermittency of wind resources [1]. Storable or adjustable energy sources, such as hydropower and compressed air energy, provide solutions to these challenges [2]. Systems that combine wind power and hydropower are the main technologies that could overcome these issues [3]. For such a combined coordinative system, it is important to identify the contribution of the hydropower company that compensates for the intermittency of wind power, and the impact on its profits. Since output fluctuation is the primary element which could reflect that compensation, a rational index to quantify the fluctuation would provide significant support to the power companies.

Indices that quantitatively evaluate output fluctuations have been proposed and applied by many researchers in the electrical research field [4]. In other fields, such as hydrological regime research [5], environmental assessment [6], and economic analysis [7], similar methods of calculating process fluctuations have also been presented. Generally, these indices can be classified into two types: quantitative and contour. 
The output of a process is always expressed in the form of a polyline in the rectangular coordinate system. The quantitative index is related to the differences in the values of the ordinates. According to the disposal of ordinate, the quantitative type is further divided into several categories. The first category is the difference value, which includes the first-order difference (FOD) [8-12], standard deviation (SD) $[4,7,13-15]$, and variation [16]. This category contains a sort of difference pattern, such as difference between adjacent ordinates, difference between ordinate and its mean. The second category is called the divided category, and it includes the FOD divided by the maximum [17], SD divided by the mean [13,14,18], coefficient of variation [19], normalized SD [20], and Richards-Baker Flashiness (RBF) index [5,19,21-24]. The third is the distribution, and contains the distribution of the FOD [4] and the distribution of exceedance [6]. These distribution indices concentrate on the frequency of variation of a certain magnitude, resulting in a group of frequencies. They cannot generate a single quantitative value to describe the fluctuation of the entire process.

The FOD, SD, and RBF indices are often used for quantitative analysis, with the FOD and SD being the most commonly used in research. The RBF, based on Indicators of Hydrological Alteration (IHA) [25] and Richards Pathlength (RP) [26], was proposed by Baker and Richards in 2004 [27] and has subsequently been widely used to describe stream flow fluctuations [5,19,21-24]. Due to ignorance of contour variation of process, the FOD, SD and RBF are capable of describing the dispersion of process but inadequate to discern the contour difference. Taking a sine/cosine process as an example, if its period changes from $2 \pi$ to $4 \pi$ then it is obvious that the process becomes flatter but retains its original SD.

The contour type takes the abscissa of process into consideration and mainly describes the shape of process, such as its slope [5,25,28,29], rotation angle [30-34], number of reversals [5,25,29,35], and length [26]. In our earlier study on quantifying fluctuation [30], the rotation angle was used to calculate the fluctuation of the combined output of a pumped storage station and a thermal station. During subsequent research [31-33], the rotation angle was consistently used to describe the output fluctuations. With shortage of counting quantitative variation, the contour type could not distinguish between similar processes, such as zigzag processes.

Considering that dispersion and shape only represent one aspect of a process output function, we propose a new index to characterize the fluctuations. Based on both quantitative and contour type indices, this index employs the SD and rotation angle to describe the fluctuations. In the subsequent discussion, first the new index is introduced. Next, the tests performed using diverse processes and various proposals confirming the validity of the proposed index are described. Then, it is applied to analyze the fluctuation of hydro-wind output.

\section{Methods and Materials}

\subsection{Methods}

The method proposed in this paper is intended to characterize the fluctuations of an output process by utilizing the SD and rotation angle.

The SD is used to describe the quantitative variations and can be calculated using Equation (1):

$$
\alpha=\sqrt{\frac{1}{N} \sum_{i=1}^{N}(y(i)-\bar{y})^{2}}
$$

where $y(i)$ is the ordinate of the process output which is expressed in the form of a polyline in the rectangular coordinate system; $i$ is the sequential number of data points of the polyline; $N$ is the total number of data points; $\bar{y}$ is the mean of the $y(i)$ values; and $\alpha$ is the quantitative variation of the process. 
The rotation angle is employed to describe the contour variations of the process output. Equations (2)-(4) can be used to calculate the rotation angle:

$$
\begin{gathered}
\beta=\sum_{i=1}^{N} \theta_{i} \\
\theta_{i}= \begin{cases}\arctan \left|k_{i}\right| & i \text { or } N \\
\left|\arctan k_{i}-\arctan k_{i-1}\right| & 2 \leqslant i \leqslant N-1, \text { and } k_{i} \times k_{i-1} \geqslant 0 \\
\arctan \left|k_{i}\right|+\arctan \left|k_{i-1}\right| & 2 \leqslant i \leqslant N-1, \text { and } k_{i} \times k_{i-1}<0\end{cases} \\
k_{i}= \begin{cases}\frac{y(i+1)-y(i)}{x(i+1)-x(i)} & 1 \leqslant i \leqslant N-1 \\
\frac{y(N)-y(N-1)}{x(N)-x(N-1)} & i=N\end{cases}
\end{gathered}
$$

where $\theta_{i}$ is the rotation angle of the process output, as shown in Figure 1 . When $2 \leqslant i \leqslant N-1, \theta_{i}$ is the rotation angle between two adjacent line segments of process, while when $i=1$ or $N$, it is the acute angle between the 1st or $N$ th line segment, respectively, and a horizontal line. The slope is represented by $k_{i}$. When $1 \leqslant i \leqslant N-1 k_{i}$ is the slope of the $i$ th line segment, while when $i=N$, it is the slope of $N-1$ th line segment. The symbol $\beta$ represents the contour variations of the process output.

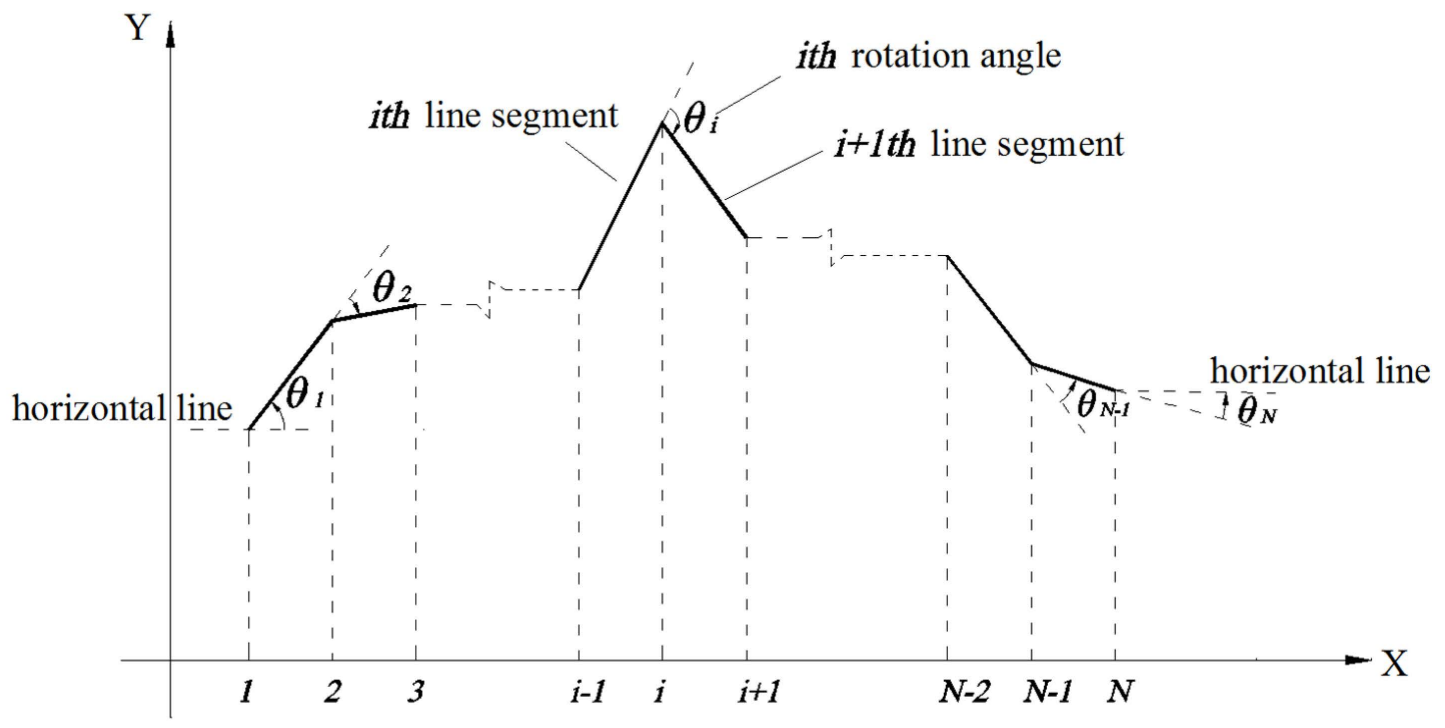

Figure 1. Diagram of rotation angle and line segment of process.

The equation of characterizing the fluctuation of process is shown in Equation (5). We refer to the new index as the Mei-Wang Fluctuation (MWF) index:

$$
F_{M W F}=\alpha \times \beta=\sqrt{\frac{1}{N} \sum_{i=1}^{N}(y(i)-\bar{y})^{2}} \times \sum_{i=1}^{N} \theta_{i}
$$

In order to testify the validity of using the MWF index to characterize the fluctuation of output process, several commonly used measures, namely, the FOD, SD, and RBF indices, were compared with the MWF index. Their functions are listed in Table 1. 
Table 1. Indices used to characterize the fluctuation of processes.

\begin{tabular}{|c|c|c|}
\hline Index & Description & Source/Reference \\
\hline First Order Difference & $F_{F O D}=\sum_{i=1}^{N-1}|y(i+1)-y(i)|$ & Reference [8] \\
\hline SD & $F_{S D}=\sqrt{\frac{1}{N} \sum_{i=1}^{N}(y(i)-\bar{y})^{2}}$ & Carl Friedrich Gauss \\
\hline Richards-Baker Flashiness (RBF) & $F_{R B F}=\frac{\sum_{i=1}^{N} 0.5(|y(i+1)-y(i)|+|y(i)-y(i-1)|)}{\sum_{i=1}^{N} y(i)}$ & Reference [27] \\
\hline Mei-Wang Fluctuation (MWF) & 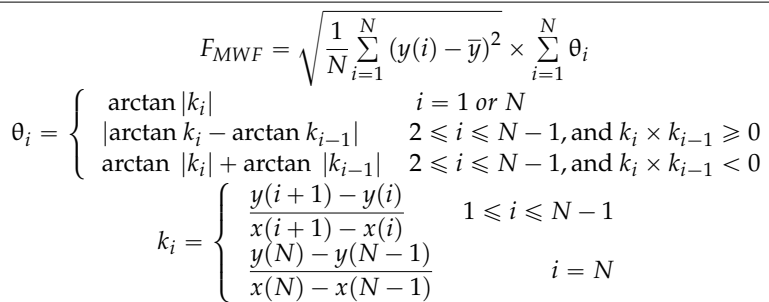 & This study \\
\hline
\end{tabular}

\subsection{Materials}

\subsubsection{Process}

To test the validity of the proposed index several types of processes were used, such as random, periodic, and observed processes. Periodic processes include zigzag and sine/cosine processes. In this study, the observed processes were the runoff and wind speed processes shown in Figures 2 and 3 respectively.

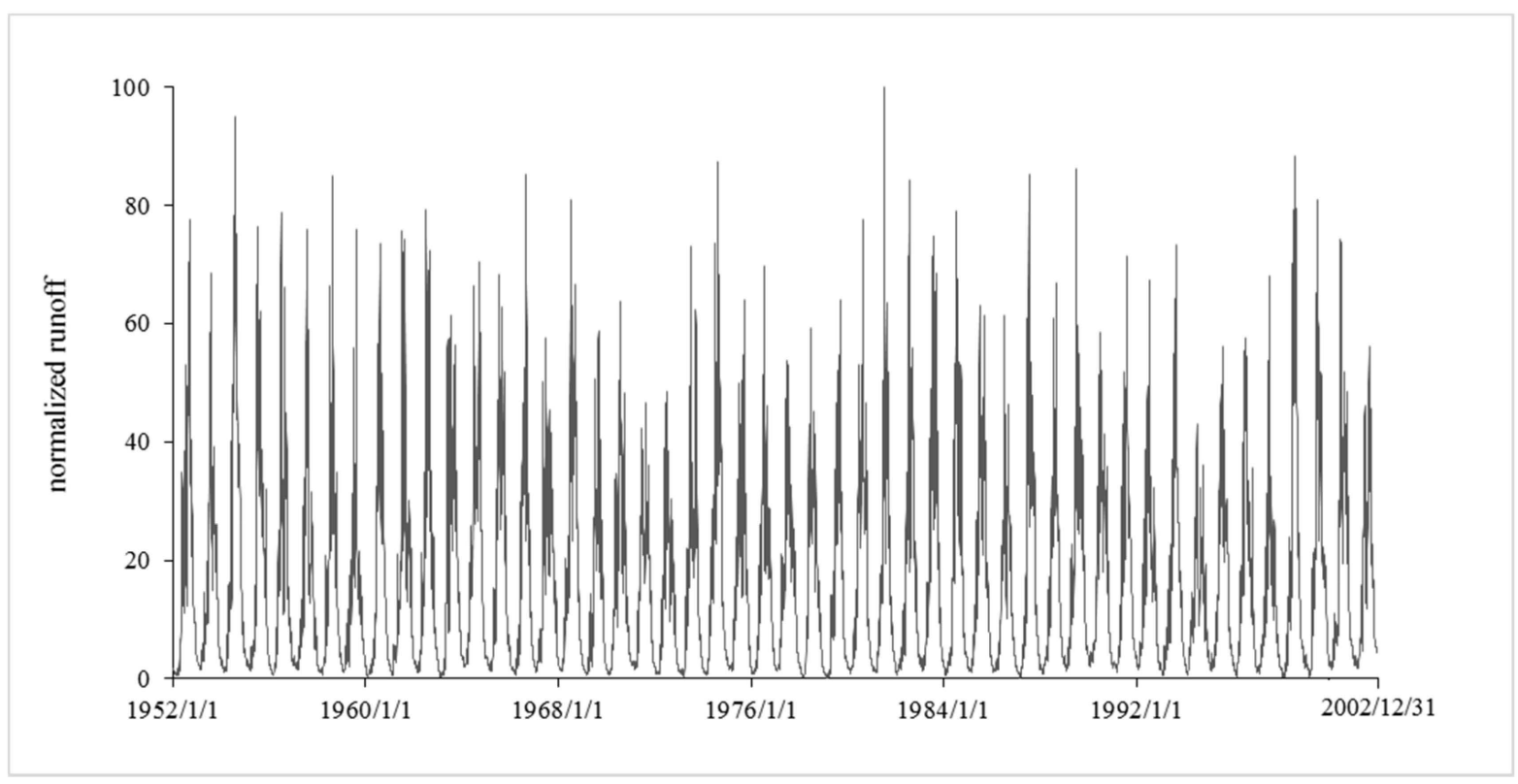

Figure 2. Normalized runoff process (from 0 to 100) analyzed in this research. Original data describe runoff measured at hydrologic station (location: $30^{\circ} 42^{\prime} \mathrm{N}, 111^{\circ} 17^{\prime} \mathrm{E}$, catchment area: $1.01 \times 10^{6} \mathrm{~km}^{2}$ ) in central China. Resolution is 1 day and duration is 50 years. 

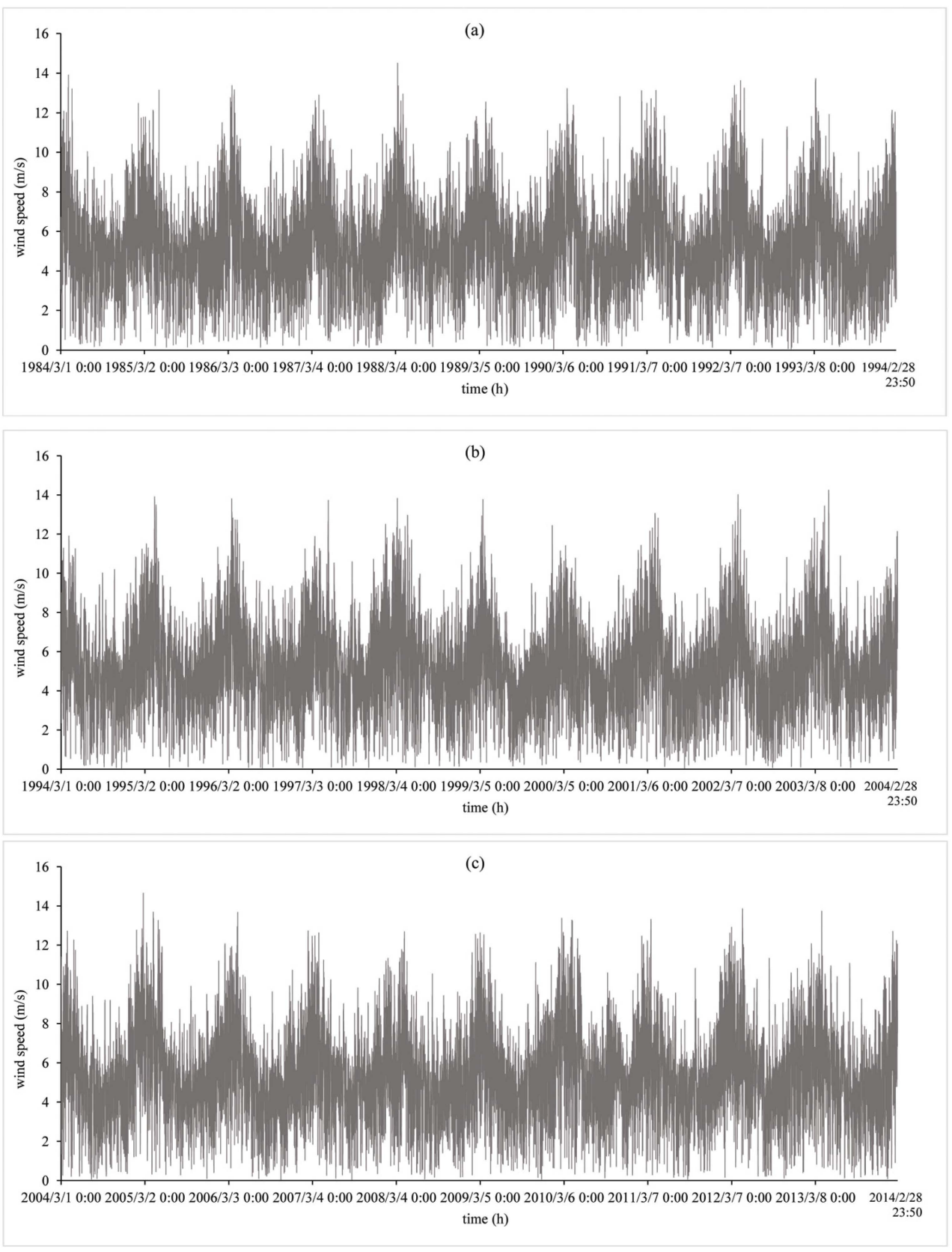

Figure 3. Wind speed process analyzed in this study. Data were downloaded using Modern-era Retrospective Analysis for Research and Applications [36], an application developed by NASA. Series covers Jinning region in southwestern China $\left(24^{\circ} 30^{\prime} \mathrm{N}, 102^{\circ} 40.13^{\prime} \mathrm{E}\right)$ with resolution of $1 \mathrm{~h}$ and duration of 30 years (from 1 March 1984 0:00 to 28 February 2014 23:50). (a) The wind speed process from 1 March 1984 0:00 to 28 February 1994 23:50; (b) The wind speed process from 1March 1994 0:00 to 28 February 2004 23:50; (c) The wind speed process from 1 March 2004 0:00 to 28 February 2014 23:50.

From Figures 2 and 3 it can be seen that both the runoff process and the wind speed process show periodical and random feature. During testing, different magnifications were adopted to obtain similar processes with different but regular fluctuation, such as abscissa zoom, ordinate zoom, and combinations of abscissa and ordinate zoom. Moreover, repeating disposal and superimposed disposal were applied. With various processes, the capability of the proposed index can be verified. 


\subsubsection{Combined Hydro-Wind Power System}

In this research, we used data obtained at an anemometer tower and a hydrologic station as the source data to simulate a combined system consisting of one wind farm and one hydropower station. The anemometer tower and hydrologic station are both located in Dayao (Yunnan, China), as shown in Figure 4 , and are separated by $40 \mathrm{~km}$. The wind speed and runoff measured at the anemometer tower and hydrologic station, respectively, during 72-h-long periods in both the flood and dry seasons were considered in our study; these are displayed in Figure 5.

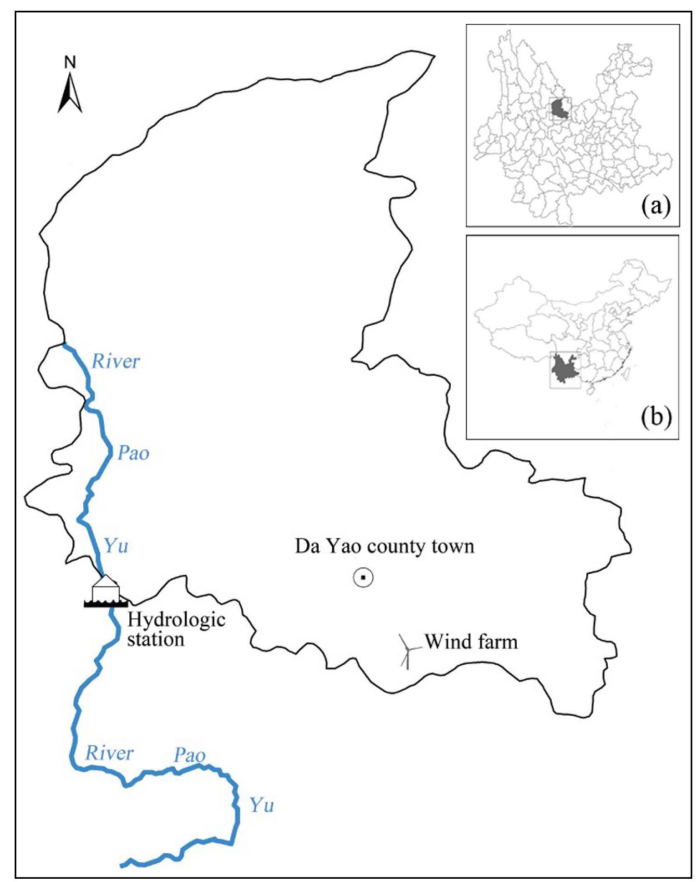

Figure 4. Locations of anemometer tower and hydrologic station. Anemometer tower is located in southern Dayao County in Yunnan Province, China $\left(25^{\circ} 36.72^{\prime} \mathrm{N}, 101^{\circ} 22.88^{\prime}\right.$ E). Hydrologic station is located in western Dayao County $\left(25^{\circ} 42.53^{\prime} \mathrm{N}, 100^{\circ} 59.6^{\prime} \mathrm{E}\right)$, and its catchment area is about $1950 \mathrm{~km}^{2}$. (a) the location of Dayao County in Yunnan Province; (b) the location of Yunnan Province in China.

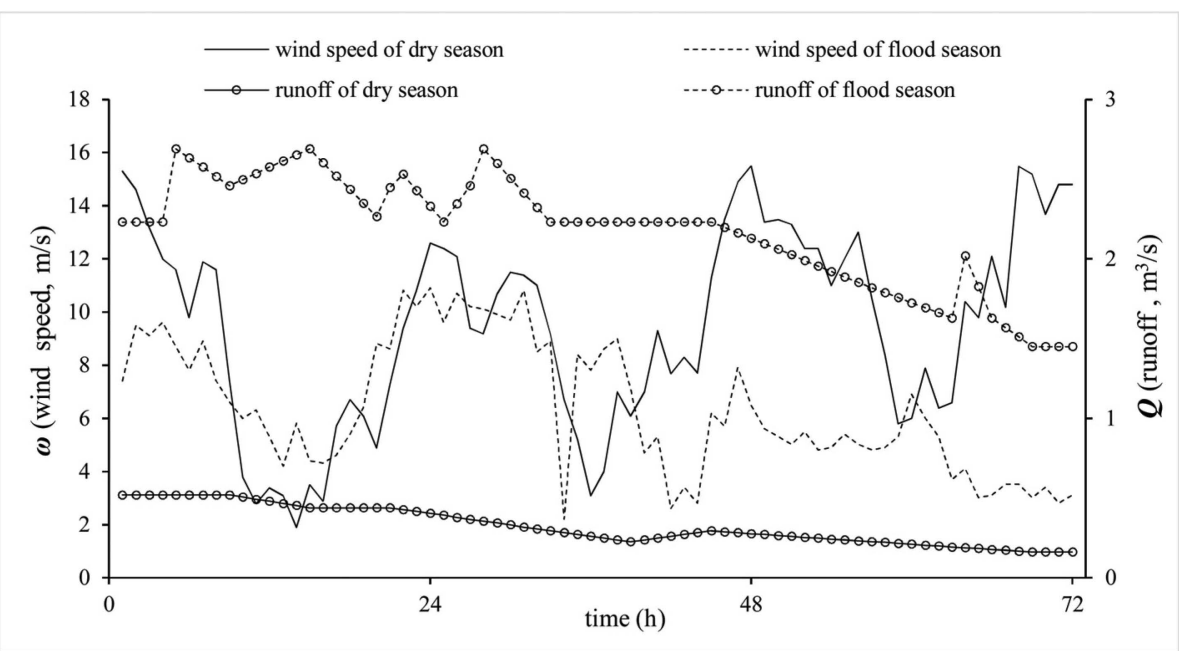

Figure 5. Wind speed and runoff measured at anemometer tower and hydrologic station, respectively, over 72-h-long periods. 


\section{Results and Discussion}

\subsection{Comparison of Indices}

In order to illustrate the abilities of the different indices to characterize process output fluctuations, various processes were examined in this study. Firstly, the shortcomings of the most commonly used indices were elucidated by applying them to special processes. Then, the validity of the proposed index was confirmed by using diverse processes and disposals.

The FOD is simple, as it only takes into the absolute difference between adjacent values account, and not the deviation, which can be described by the SD. From Figure 6a, it can be seen that the FODs of the two investigated process are the same, but the deviation of the dashed line is apparently larger than that of the solid line. Even the SD index has exceptional case. As shown in Figure 6b, their SDs are the same, while the fluctuations are apparently different. The SD only accounts for the deviation of the output and not for its contour variations. As for the RBF index, it cannot distinguish between processes with different scales of ordinates, as shown in Figure 6c. The ordinate of each point on the dashed line in Figure $6 \mathrm{c}$ is four times the corresponding ordinate of the solid line, though their RBF indices are same, because the ordinates existing in both the numerator and denominator of the RBF function (as shown in Table 1) are homogeneous. Thus, scaling the ordinate by a constant factor would not induce any change in the RBF index.

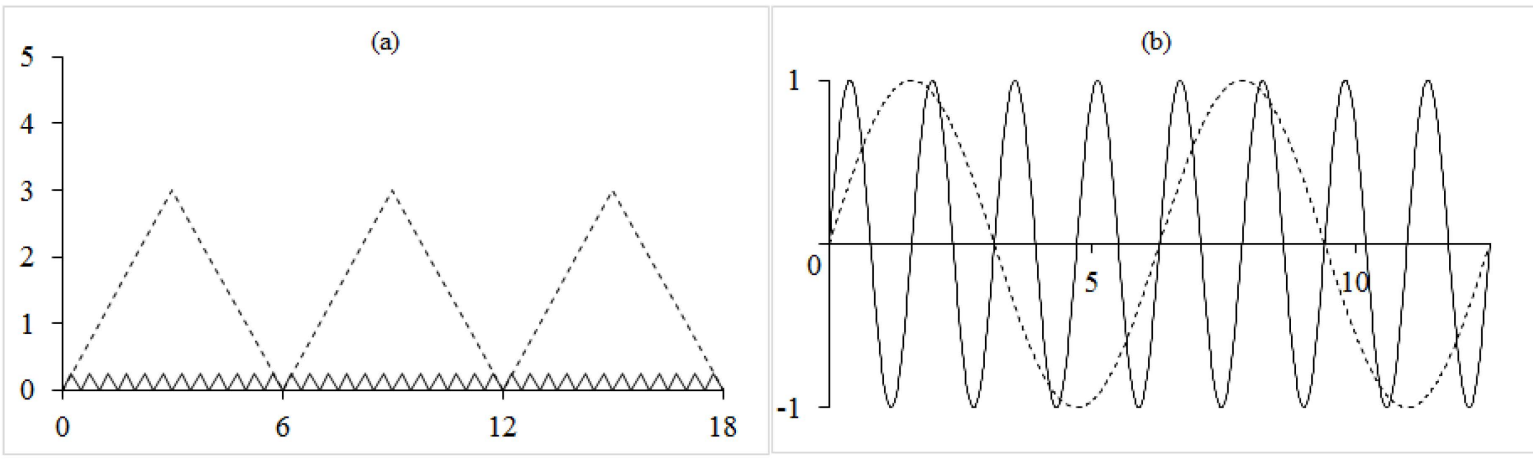

(c)

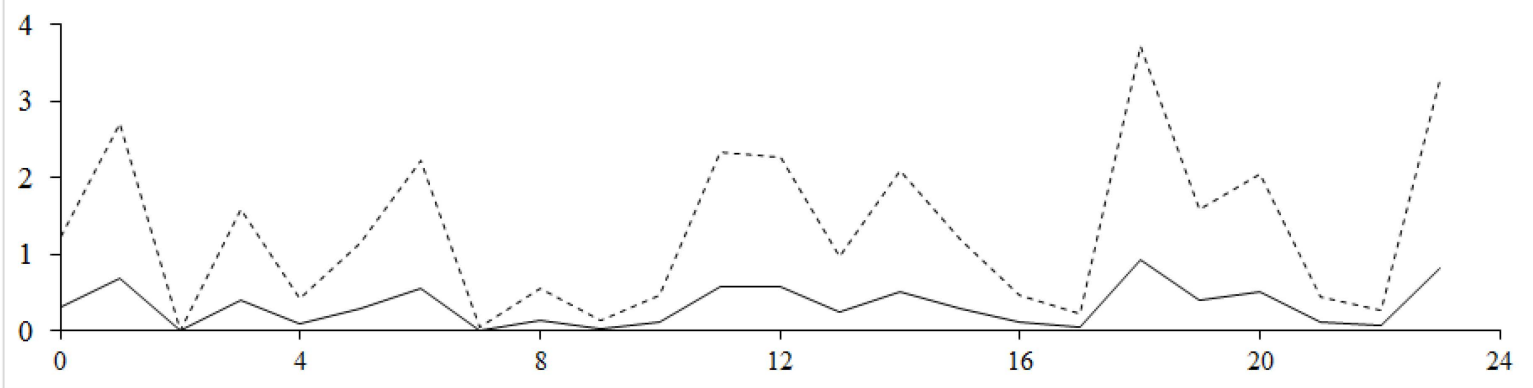

Figure 6. Processes for special case. (a) the zigzag processes; (b) the sine/cosine processes; (c) similar processes with different scale of ordinates.

Moving average disposal can be used to reduce process fluctuations. As the length of a moving segment (s) increases, the disposed process becomes flatter. When s equals the length of the entire process $(N)$, the disposed process becomes a horizontal line, which has no fluctuation. In this study, various segment lengths, from 2 to $N$, were employed. To maintain the length of the disposed process same, the head and tail of the process were connected. If $s=3$, for example, the first data point of the disposed process was determined by averaging the first three data points of the original process, and the last data point of the disposed process was calculated by averaging the last and first two data points of the original process. With a random process shown in Figure 7a (its ordinate value ranging 
from 0 to $1, N=100$ ), the results of the four indices are shown in Figure $7 \mathrm{~b}, \mathrm{c}$. In these results, the trends are similar for all of the indices, which all exhibit rapid decreases initially and gradual declines towards the end. Thus, the quantification of the fluctuation reduction caused by moving average disposal is similar for the MWF index and for the other three indices.

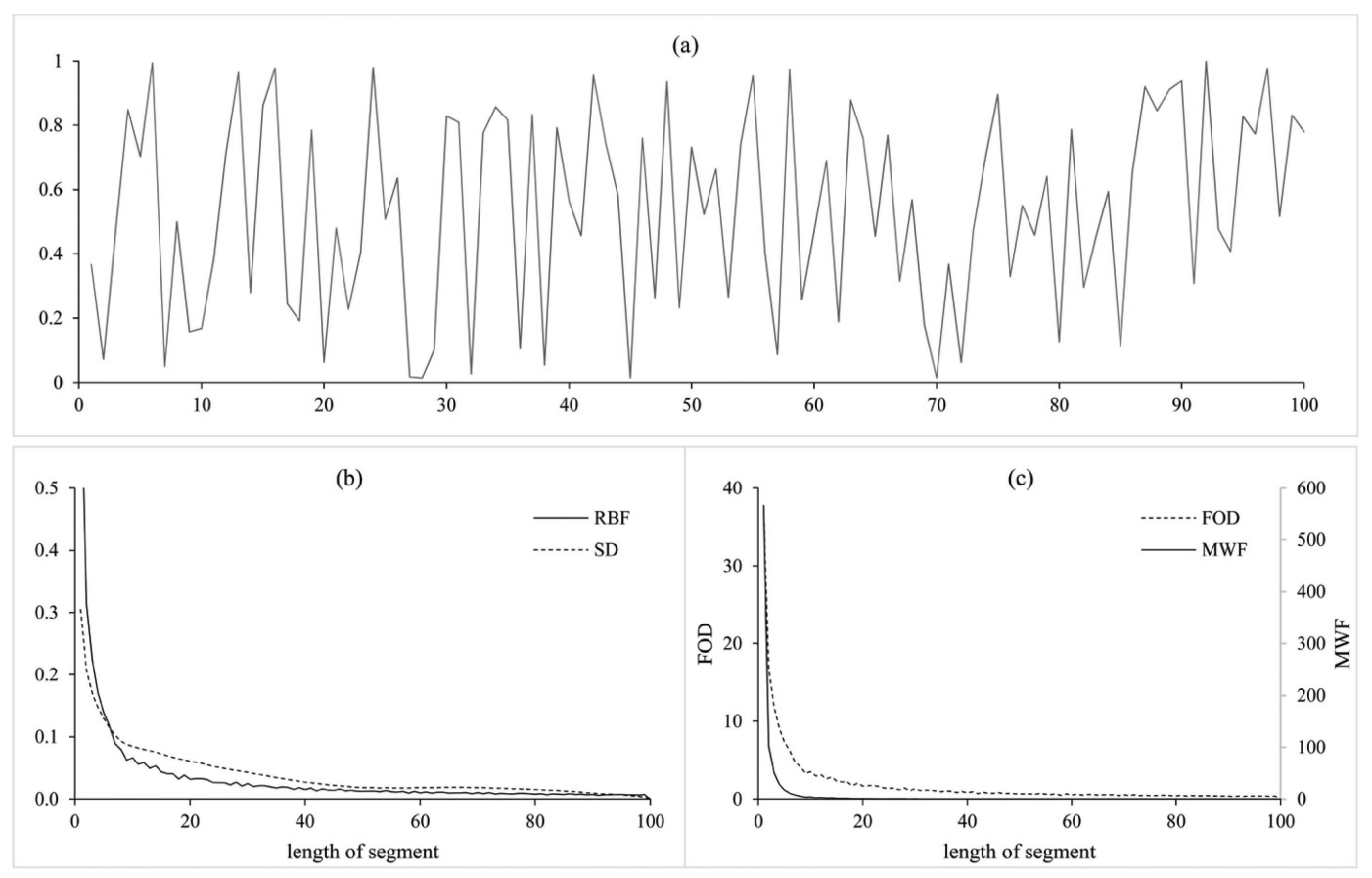

Figure 7. Comparison of indices with different moving average disposals. (a) a random process with 100 data points and its ordinates range from 0 to 1 ; (b) the RBF or SD indices of disposed process with segment length ranging from 2 to $N$; (c) the FOD or MWF indices of disposed process with segment length ranging from 2 to $N$.

Performing the process a second time would double the fluctuations. Therefore, there is a linear relationship between the number of repetitions and the fluctuation of a process. The indices obtained for a random process (solid line in Figure 6c) with several repetitions $\{1,2,3,4,5,6,7,8,9,10\}$ are displayed in Figure 8. The SD and RBF indices remain constant, while the FOD and MWF indices increase linearly with the number of repetitions. Thus, the SD and RBF indices do not reflect the repeating fluctuations, while the FOD and MWF do.

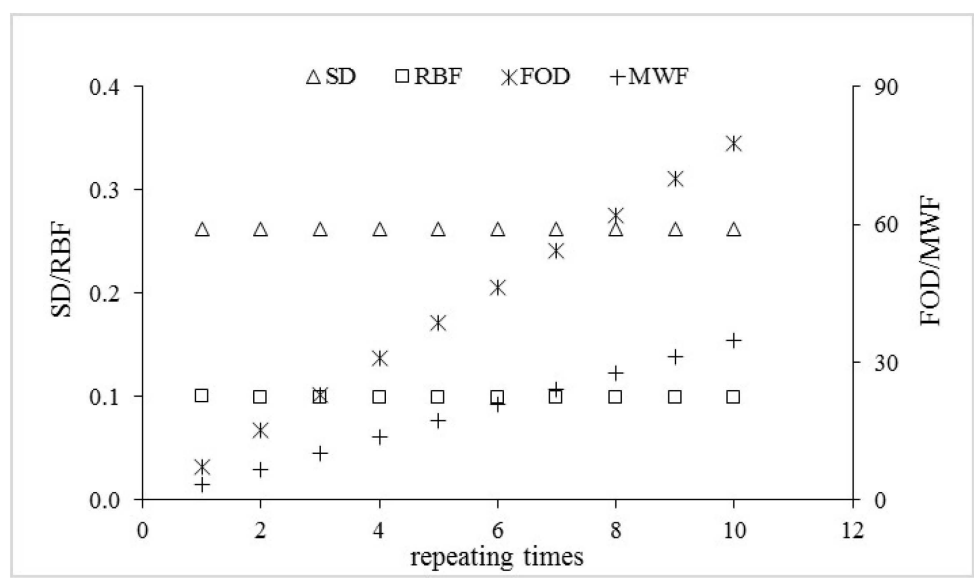

Figure 8. Comparison of indices with different numbers of repetitions. 
To fully determine the capabilities of the different indices, a random process (the ordinate values ranging from 0 to 1 , corresponding to the solid line in Figure $6 \mathrm{c}$ was investigated using different zoom patterns. It is obvious that using a larger zoom for the abscissa with a fixed ordinate makes the process flatter and the fluctuation index of the process smaller, while using a larger zoom for the ordinate with a fixed abscissa makes it sharper and its fluctuation index larger. Moreover, a larger zoom for both the abscissa and the ordinate does not lead to any change in the geometric shape but does lead to quantitative increases, and the value of fluctuation index becomes larger too. A flatter process should yield a smaller fluctuation index, while a sharper process should yield a larger fluctuation index. In view of this, the MWF index was investigated to verify whether it would meet this expectation. The zoom pattern used for scaling was a $19 \times 19$ matrix, and zoom values of the abscissa and ordinate are $\{0.1,0.2,0.3,0.4,0.5,0.6,0.7,0.8,0.9,1,2,3,4,5,6,7,8,9,10\}$. During the zoom operation, the process resolution was kept for comparison at same boundary. The results are shown in Figure 9 . The MWF index matches with the change in fluctuation under various zoom patterns, as in the preceding discussion, while this is not the case with the other three indices. There are no changes in the FOD and SD indices when the abscissa zoom is changed, while the RBF index does not change when the ordinate zoom is changed. Thus, since the process analyzed in this comparison was random and the relationship between the zoom and fluctuation is universal, it can be concluded that the MWF index is superior to the other three indices.
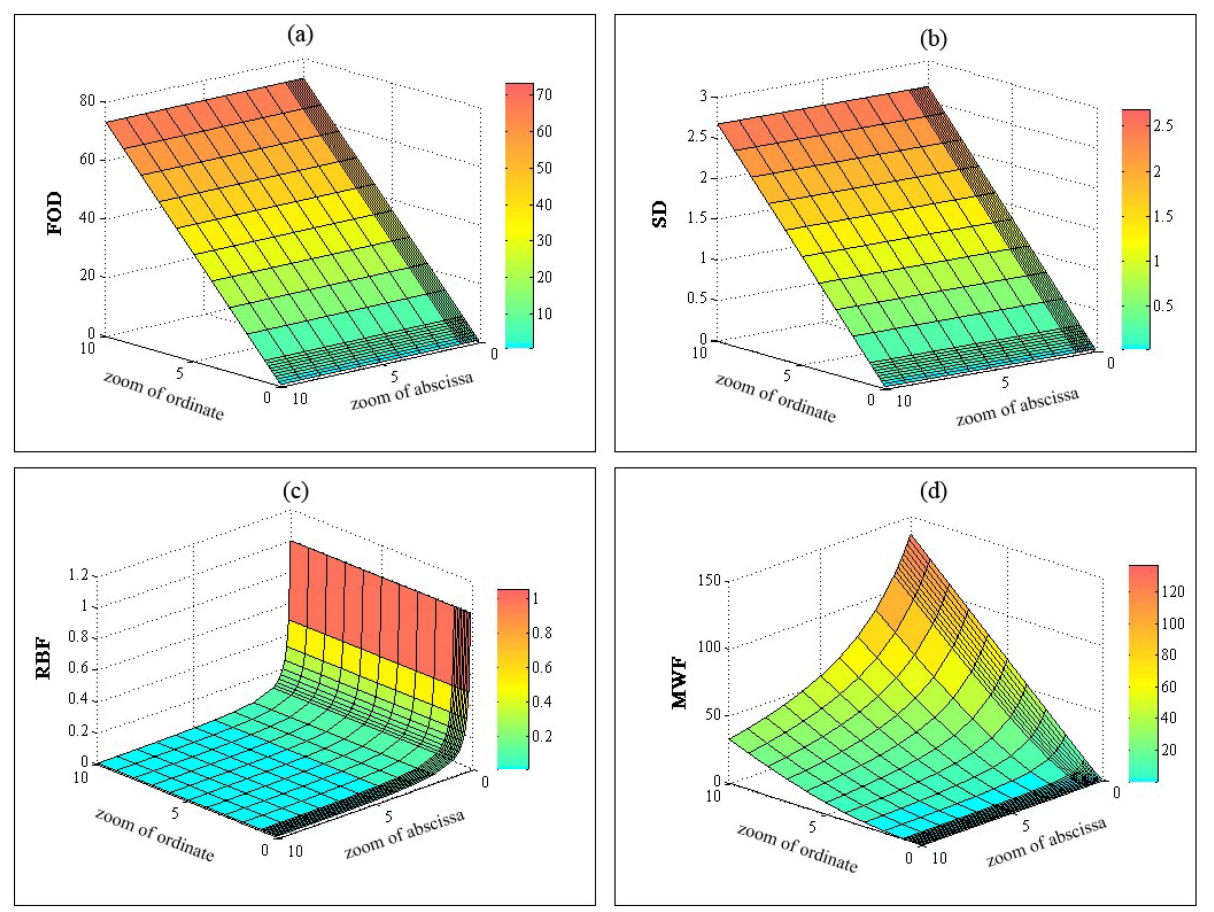

Figure 9. Comparison of indices with different zoom patterns. (a) the FOD index; (b) the SD index; (c) the RBF index; (d) the MWF index.

In order to investigate the abilities of the indices to describe wind speed and runoff processes, these processes were analyzed. The wind speed process function displayed in Figure 3 was transformed into a $24 \times \mathrm{n}$ matrix, with the $i$ th column showing the process of wind speed of the $i$ th day. By superimposing the previous $i$ columns in this matrix and calculating the mean value, a wind speed overlay matrix was obtained. As it is a natural phenomenon, wind exhibits diel alternation. With increasing $i$, the $i$ th column of the wind speed overlay matrix should approach the natural diel alternation of wind. In other words, its fluctuation should gradually tend towards to a certain value. In this study, we calculated the fluctuations of 30 years of wind speed data, and the results are displayed in Figure 10. Initially, the fluctuation index oscillates due to the random nature of wind. However, 
as $i$ increases, the diel alternation becomes more apparent, and the index variations decrease. This tendency matches with the abovementioned natural characteristic of wind.
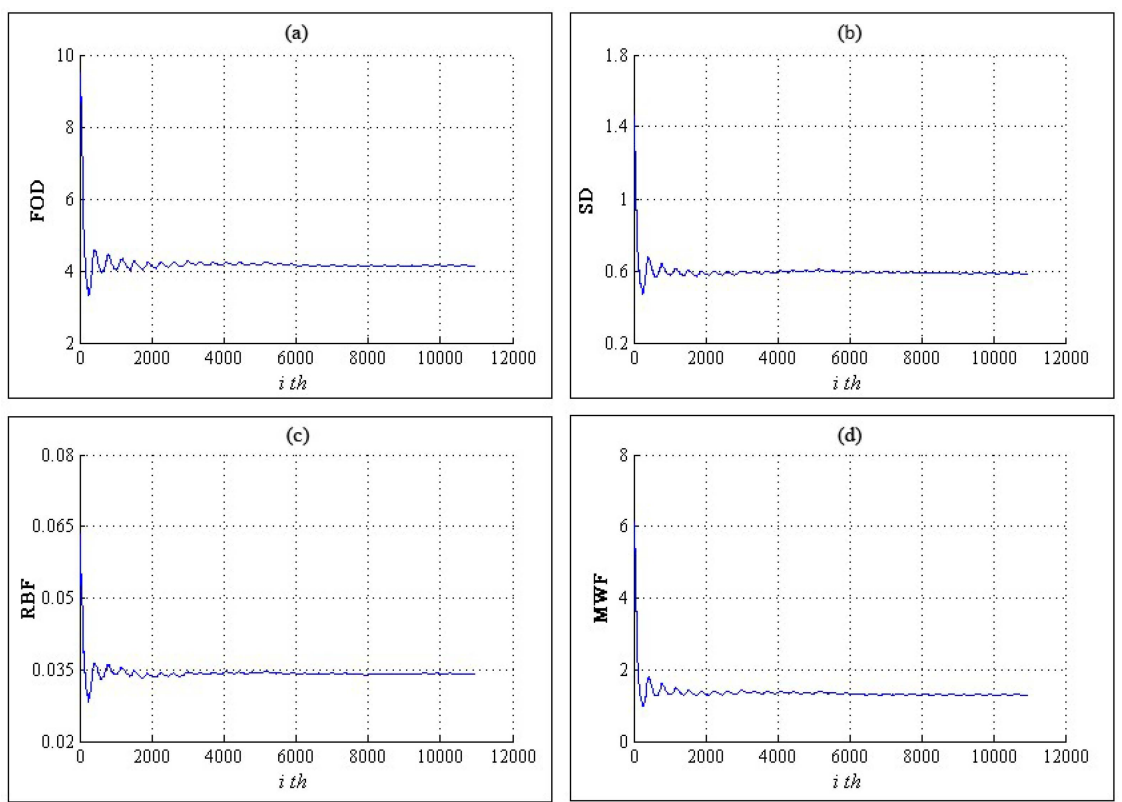

Figure 10. Comparison of indices obtained using overlay wind speed matrix. The symbol $i$ is the column number of the overlay wind speed matrix. (a) the FOD index; (b) the SD index; (c) the RBF index; (d) the MWF index.

As for runoff, runoff regularly fluctuates on an annual basis. Thus, in multiple year process of runoff, the same oscillations should be found. In this study, the runoff process (shown in Figure 2) was transformed into a $365 \times$ n matrix, where the runoff occurring on 29 February of each leap year was ignored for the convenience of overlay disposal.
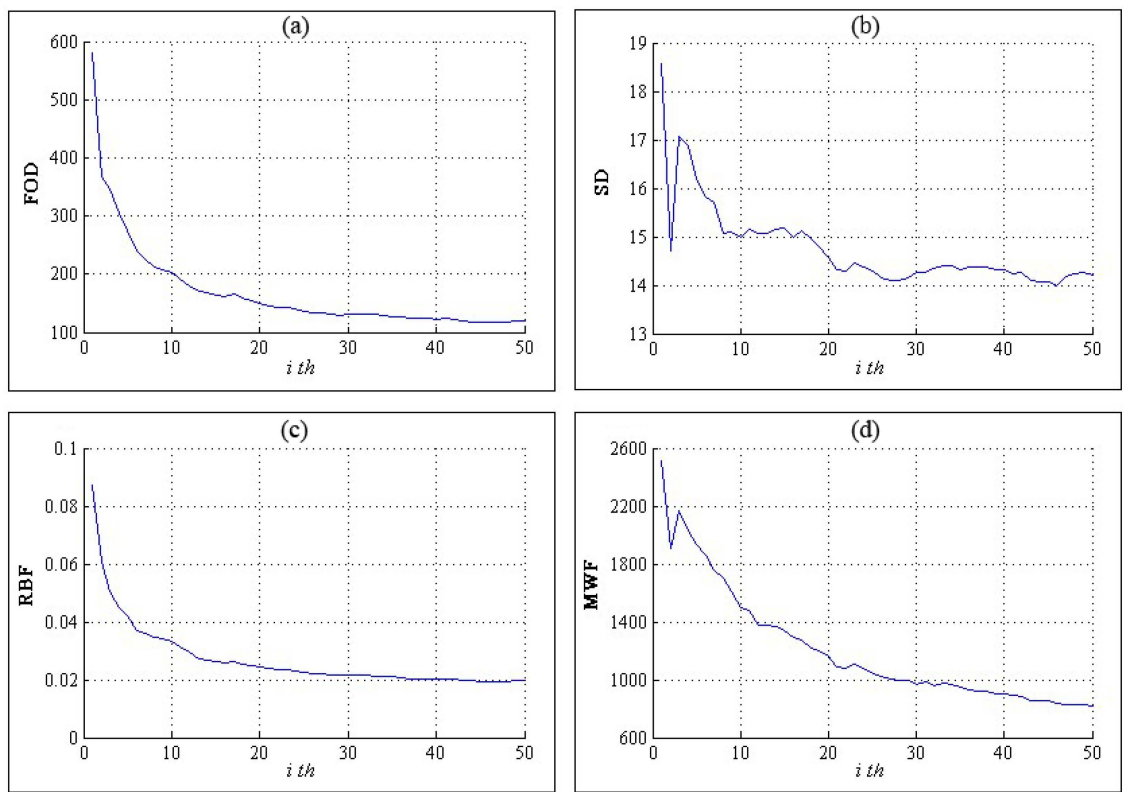

Figure 11. Comparison of indices obtained using overlay runoff matrix. The symbol $i$ is the column number of the overlay runoff matrix. (a) the FOD index; (b) the SD index; (c) the RBF index; (d) the MWF index. 
The fluctuations of the indices calculated using the runoff overlay matrix are shown in Figure 11. The SD and MWF indices clearly oscillate, but only minor oscillations can be seen in the values of the FOD and RBF indices. Thus, in this runoff case study, the MWF and SD indices could detect the oscillations and are therefore more sensitive for describing fluctuations.

The above comparisons performed using diverse processes and various disposals confirm the ability of the MWF index to characterize process fluctuations. The results are extracted and displayed in Table 2. When dealing with the process by moving average, repeating, or overlay disposal, the MWF index performs comparably to the other indices, while dealing with the process by zooming disposal, it displays superiority on capturing the fluctuation characteristics by taking both quantitative and contour variations into consideration. Therefore, the MWF index is more appropriate for quantifying process fluctuations.

Table 2. Comparison of index performances in various disposal.

\begin{tabular}{ccccc}
\hline Disposal & FOD & SD & RBF & MWF \\
\hline moving average & $\star$ & $\star$ & $\star$ & $\star$ \\
repeating & $\star$ & $\triangle$ & $\triangle$ & $\star$ \\
zoom & $\triangle$ & $\triangle$ & $\triangle$ & $\star$ \\
overlay of wind speed & $\star$ & $\star$ & $\star$ & $\star$ \\
overlay of runoff & $\triangle$ & $\star$ & $\triangle$ & $\star$
\end{tabular}

The symbol $\star$ indicates that the index could quantify the fluctuations, and $\triangle$ indicates that the index could not.

\subsection{Combined Output of Wind Power and Hydropower}

The fluctuation of the combined output of wind power and hydropower is the primary factor that reflects the compensation of hydropower. The less the combined output fluctuation, the greater the contribution of hydropower. A model for minimizing the combined output fluctuation was built based on a virtual system consisting of one wind farm and one hydropower station. The virtual system is a standalone hydro-wind power system, which facilitates analyzing the compensation of hydropower.

The functions related to the object of model are as follows:

$$
\begin{gathered}
\min \left[F_{\mathrm{MWF}}\left(P_{\mathrm{co}}\right)\right] \\
\theta_{i}= \begin{cases}\arctan \left|k_{i}\right| & i=1 \text { or } N \\
\left|\arctan k_{i}-\arctan k_{i-1}\right| & 2 \leqslant i \leqslant N-1, \text { and } k_{i} \times k_{i-1} \geqslant 0 \\
\arctan \left|k_{i}\right|+\arctan \left|k_{i-1}\right| & 2 \leqslant i \leqslant N-1, \text { and } k_{i} \times k_{i-1}<0\end{cases} \\
k_{i}= \begin{cases}\frac{1}{N} \sum_{i=1}^{N}\left(p_{\mathrm{co}}(i)-\overline{p_{\mathrm{co}}}\right)^{2} \times \sum_{i=1}^{N} \theta(i)-p_{\mathrm{co}}(i) \\
\frac{p_{\mathrm{co}}(N)-p_{\mathrm{co}}(N-1)}{t(N)-t(N-1)} & 1 \leqslant i \leqslant N-1\end{cases}
\end{gathered}
$$

where $F_{\mathrm{MWF}}$ represents the combined output fluctuation; $P_{\mathrm{co}}$ is the combined process output, which consists of data points whose coordinates are $t(i)$ and $p_{\mathrm{co}}(i) ; p_{\mathrm{co}}(i)$ is the combined output in period $t(i)$; $i$ is the sequential number of data points; $N$ is the total number of data points; $\overline{p_{\mathrm{co}}}$ is the mean of the $p_{\mathrm{co}}(i)$ series; $\theta(i)$ is the $i$ th rotation angle between the $i$ th and $i+1$ th segments of $P_{\text {co; }}$ and $k_{i}$ is the slope of the $i$ th segment.

Equations (6)-(9) are subject to the following constraints:

$$
p_{\mathrm{co}}(i)=p_{\mathrm{w}}(i)+p_{\mathrm{h}}(i)
$$




$$
\begin{gathered}
p_{\mathrm{W}}(i)= \begin{cases}p_{\mathrm{w}}(i)=0 & \omega(i)<\omega_{\text {cut-in }} \text { or } \omega(i) \geqslant \omega_{\text {cut-out }} \\
p_{\mathrm{w}}(i)=f[\omega(i)] & \omega_{\text {cut-in }} \leqslant \omega(i)<\omega_{\text {cut-out }}\end{cases} \\
p_{\mathrm{h}}(i)=\lambda(i) \times p_{\mathrm{h}}^{\max }(i) \\
p_{\mathrm{h}}^{\max }(i)=\max \left[P_{\mathrm{h}}^{C}, p_{\mathrm{h}}^{e}(i)\right] \\
p_{\mathrm{h}}^{\mathrm{e}}(i)=\eta \times q(i) \times h
\end{gathered}
$$

where $p_{\mathrm{w}}(i)$ is the wind farm output in period $t(i) ; \omega(i)$ is the wind speed, $f[\omega(i)]$ is the relationship between $\omega(i)$ and $p_{\mathrm{w}}(i) ; \omega_{\text {cut-in }}$ and $\omega_{\text {cut-out }}$ are the cut-in and cut-out wind speeds of a wind turbine, respectively; $p_{\mathrm{k}}(i)$ is the dispatched hydropower output in period $t(i) ; \lambda(i)$ is the portion of hydropower output that could be combined with $p_{\mathrm{w}}(i) ; p_{\mathrm{h}}^{\max }(i)$ is the maximum hydropower output; $P_{\mathrm{h}}^{\mathrm{C}}$ is the hydropower capacity, $p_{\mathrm{h}}^{\mathrm{e}}(i)$ is the hydro-energy of the runoff; $\eta$ is the hydropower output power coefficient; $q(i)$ is the runoff in period $t(i)$; and $h$ is the water head of hydropower.

The wind power output is unadjustable. Thus, the fluctuation of the combined output $F_{\mathrm{MWF}}\left(P_{\mathrm{co}}\right)$ is determined by the dispatched hydropower output, which further depends on $\lambda(i)$ and $p_{h}^{\max }(i)$. When $p_{h}^{\max }(i)$ is settled, $F_{\mathrm{MWF}}\left(P_{\mathrm{co}}\right)$ is determined by $\lambda(i)$. Therefore, if $p_{\mathrm{h}}^{\max }(i)$ is given, there is a corresponding minimum $F_{\mathrm{MWF}}\left(P_{\mathrm{co}}\right)$ that depends upon the optimal $\lambda(i)$. The value of $p_{\mathrm{h}}^{\max }(i)$ is limited by the hydropower capacity and available water resources. In this study, a group of hydropower capacities (from small to large) and two water resource scenarios (flood season and dry season) were analyzed. The other parameters in this model were held constant.

The decision variables of the optimization model are $\lambda(i)$, which range from 0 to 1 . $i$ is integer number from 1 to 72 . With regard to hydropower, the hydropower output power coefficient, $(\eta)$, is 8.3 and the water head, $(h)$, is $200 \mathrm{~m}$. As for the wind farm, the relationship between wind speed and output are listed in Table 3. The cut-in and cut-out wind speeds of the wind turbine are $3 \mathrm{~m} / \mathrm{s}$ and $22 \mathrm{~m} / \mathrm{s}$, respectively. The runoff process of hydropower and wind speed process of wind power are displayed in Figure 5. In the case study, the capacity of wind power is $1.5 \mathrm{MW}$ and its generator type is doubly-fed induction generator. The capacity of hydropower ranges from 0.1 to $1.6 \mathrm{MW}$. The Genetic Algorithm Toolbox of MATLAB (MATLAB R2014a) is used to optimize the combined system of wind power and hydropower.

Table 3. The relationship between wind speed and wind power.

\begin{tabular}{cccccc}
\hline wind speed (m/s) & 3 & 4 & 5 & 6 & 7 \\
wind power (MW) & 0.03 & 0.09 & 0.18 & 0.32 & 0.52 \\
wind speed (m/s) & 8 & 9 & 10 & 11 & 22 \\
wind power (MW) & 0.78 & 1.09 & 1.42 & 1.5 & 1.5 \\
\hline
\end{tabular}

The results are displayed in Table 4 and Figures 12-14. As shown, when $P_{\mathrm{h}}^{C}$ increases, the minimum $F_{\mathrm{MWF}}\left(P_{\mathrm{co}}\right)$ value decreases. When $P_{\mathrm{h}}^{\mathrm{C}}$ is small, a small increase in $P_{\mathrm{h}}^{\mathrm{C}}$ causes a notable decrease in the minimum $F_{\mathrm{MWF}}\left(P_{\mathrm{co}}\right)$ value; however, when $P_{\mathrm{h}}^{\mathrm{C}}$ is large, with the same small increase in

\begin{tabular}{|c|c|c|c|c|c|c|c|c|c|}
\hline \multicolumn{2}{|c|}{ Hydropower Capacity (MW) } & 0.1 & 0.2 & 0.3 & 0.4 & 0.5 & 0.6 & 0.7 & 0.8 \\
\hline \multirow{2}{*}{ Minimum $F_{\mathrm{MWF}}\left(P_{c o}\right)$} & Flood Season & 6.13 & 3.74 & 2.41 & 1.71 & 1.20 & 0.8 & 0.52 & 0.34 \\
\hline & Dry Season & 6.84 & 4.84 & 3.35 & 2.53 & 2.22 & 2.02 & 1.85 & 1.78 \\
\hline \multicolumn{2}{|c|}{ Hydropower Capacity (MW) } & 0.9 & 1 & 1.1 & 1.2 & 1.3 & 1.4 & 1.5 & 1.6 \\
\hline \multirow{2}{*}{ Minimum $F_{\mathrm{MWF}}\left(P_{c o}\right)$} & Flood season & 0.22 & 0.15 & 0.07 & 0.04 & 0 & 0 & 0 & 0 \\
\hline & Dry season & 1.78 & 1.74 & 1.74 & 1.74 & 1.74 & 1.74 & 1.74 & 1.74 \\
\hline
\end{tabular}
$P_{\mathrm{h}}^{\mathrm{C}}$, the effect is less.

Table 4. Minimum $F_{M W F}(P c o)$ values corresponding to various hydropower capacity and water resource constraints. 


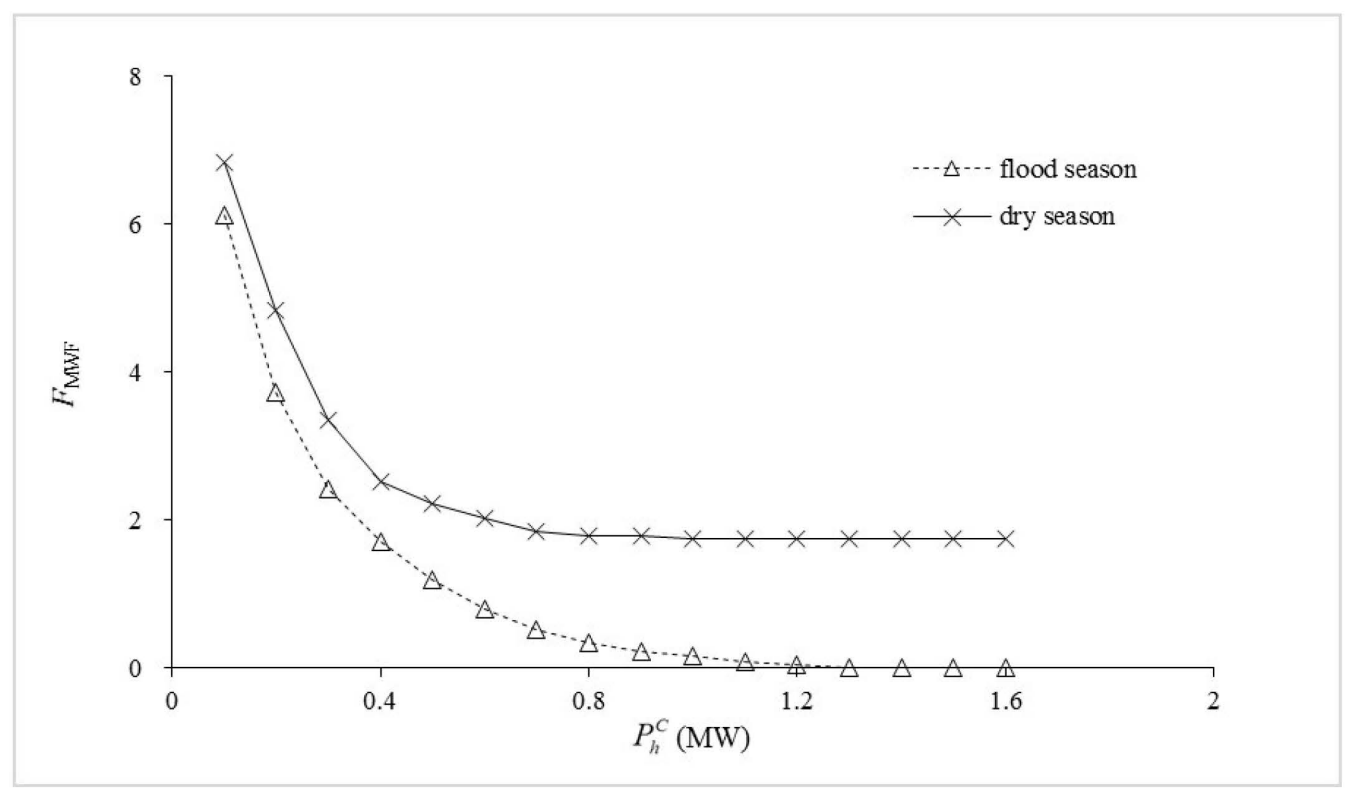

Figure 12. Combined power fluctuation index vs. hydropower capacity in different water resource conditions.

This observation is in accordance with the discipline that with limitation of hydro-energy utilization rate the compensation of hydropower becomes bigger but slower when $P_{\mathrm{h}}^{\mathrm{C}}$ is increasing. In the dry season, the minimum $F_{\mathrm{MWF}}\left(P_{\mathrm{co}}\right)$ value could not be reduced to zero (as shown in Figure 13i-p), while in the flood season, the hydropower could fully transform the combined output into a constant output that had no fluctuation (as shown in Figure 14o-p). These results match with the mechanism of hydro-wind systems. As is well known, the ability of hydropower to compensate for wind power fluctuations is limited by the hydropower capacity and water resources, and without those limitations the fluctuations could be completely eliminated. From this case study, it can be seen that it is appropriate to apply the MWF index in quantifying the combined output of wind power and hydropower.
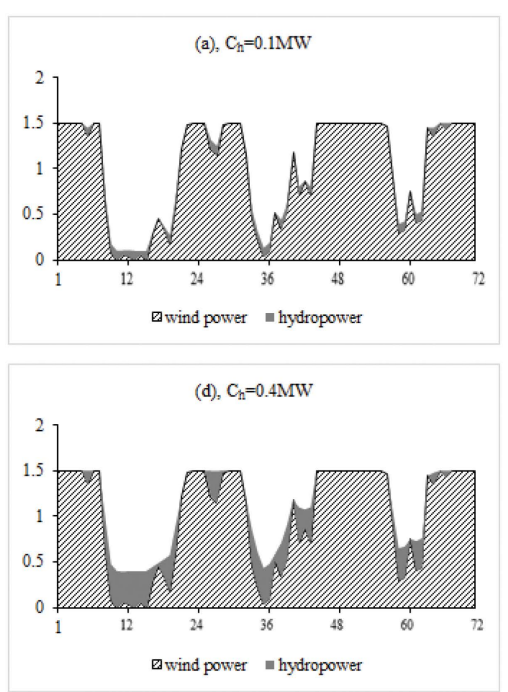
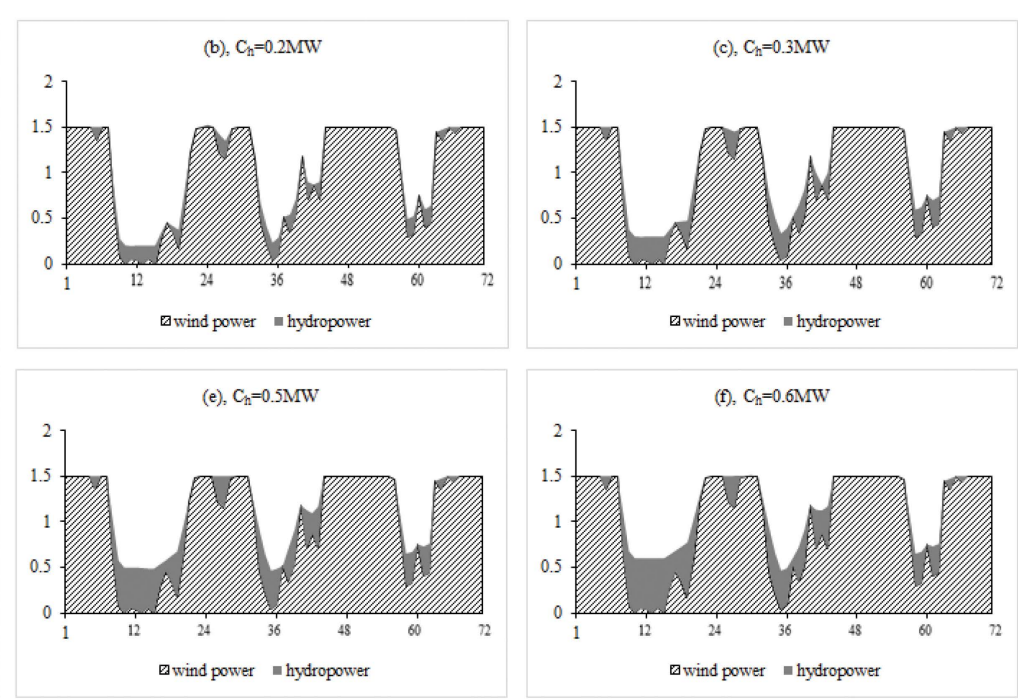

Figure 13. Cont. 

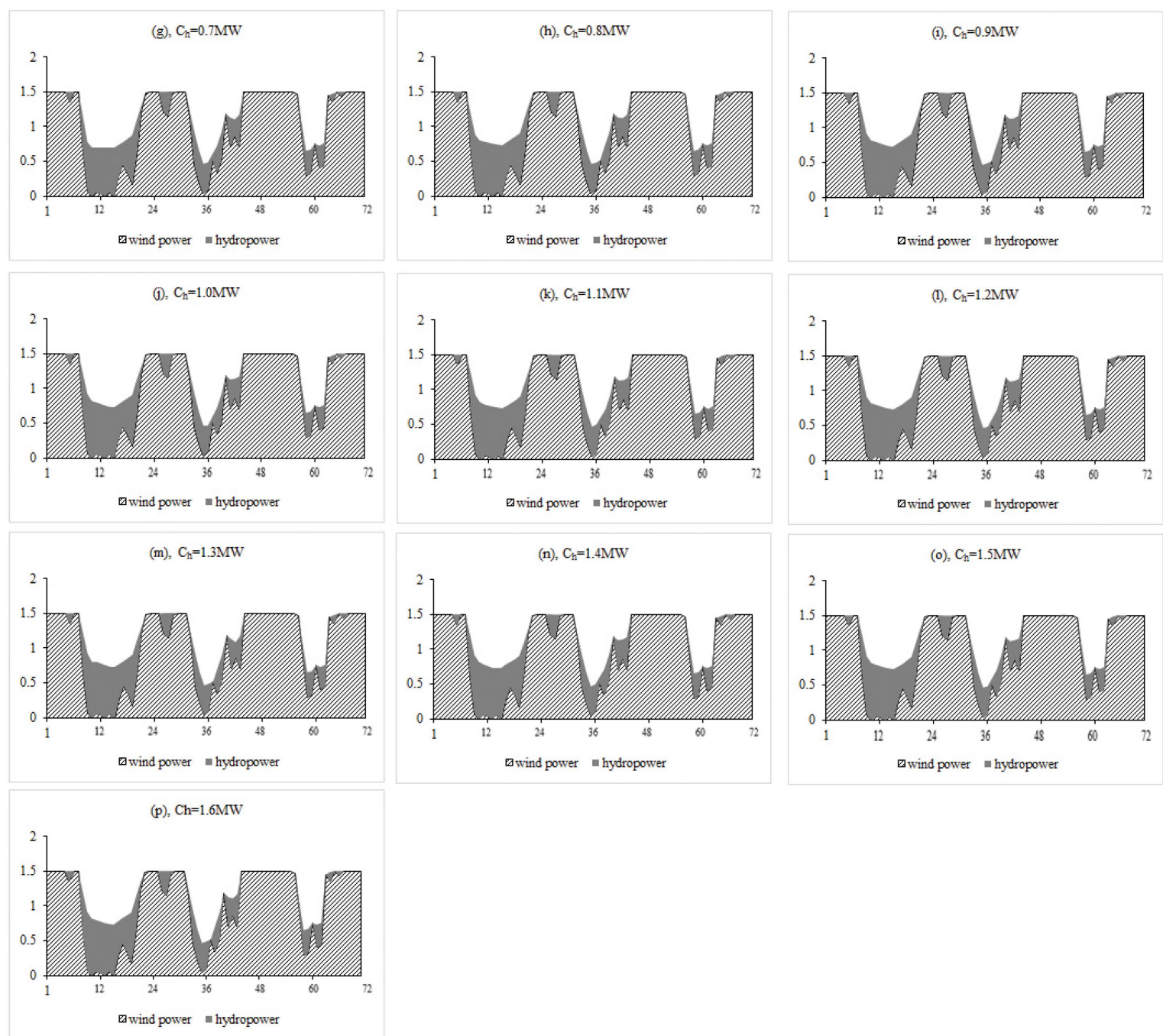

Figure 13. Combined output with different hydropower capacities in dry season. (a) the combined output with hydropower capacities of $0.1 \mathrm{MW} ;(\mathbf{b})$ the combined output with hydropower capacities of $0.2 \mathrm{MW} ; \ldots ;(\mathbf{p})$ the combined output with hydropower capacities of $1.6 \mathrm{MW}$.
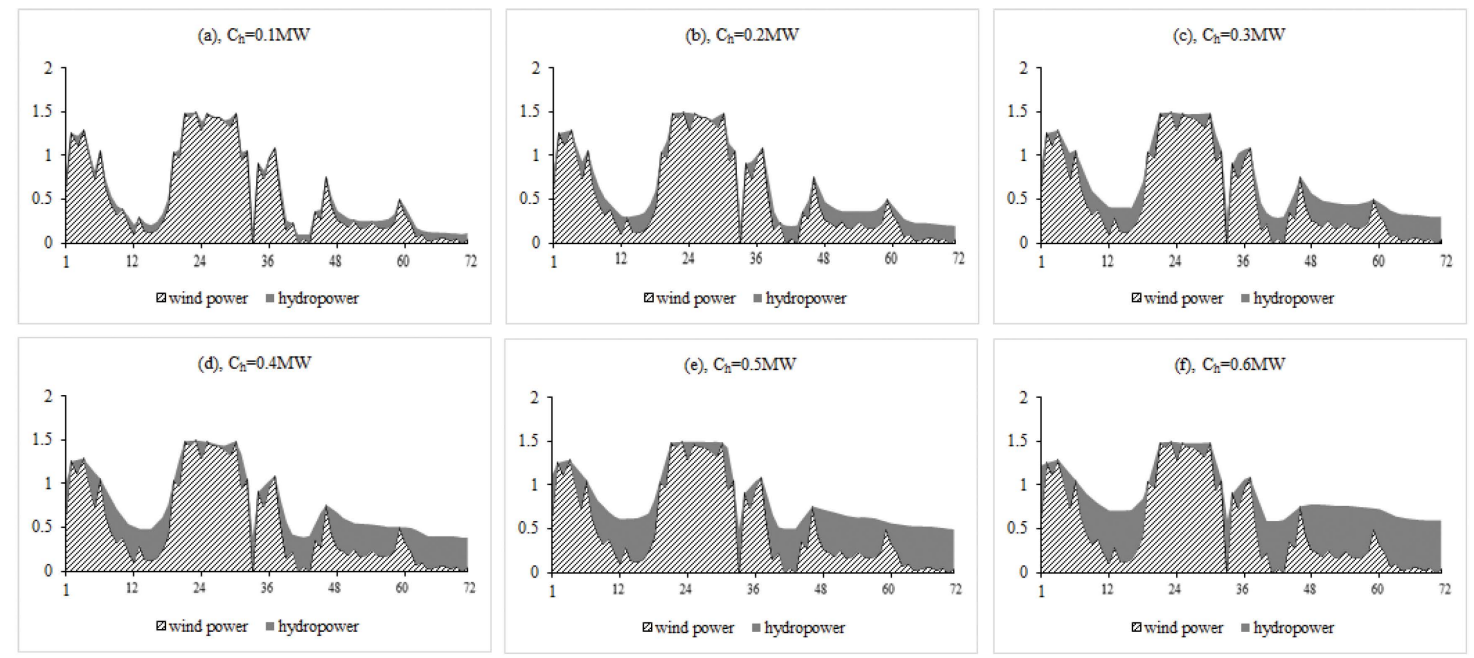

Figure 14. Cont. 


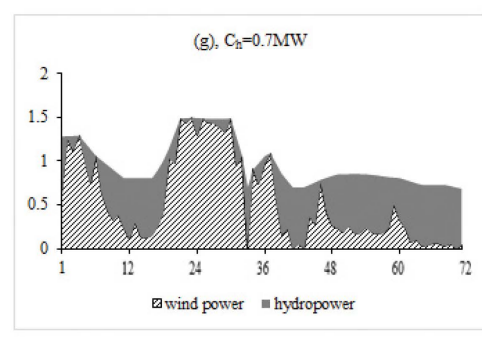

(j), $\mathrm{C}_{\mathrm{n}}=1.0 \mathrm{MW}$

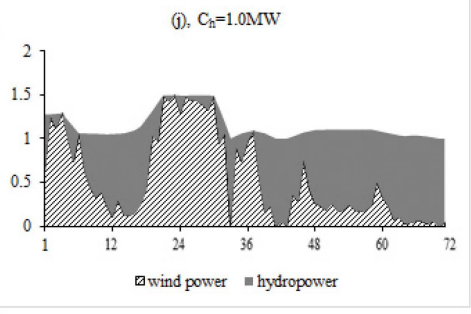

(m), $\mathrm{C}_{\mathrm{h}}=1.3 \mathrm{MW}$

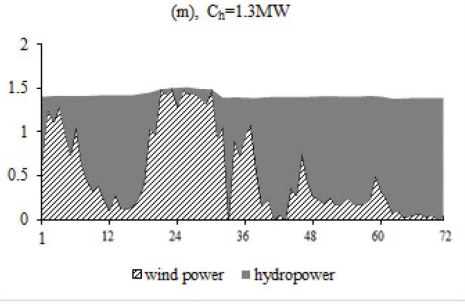

(p), $\mathrm{Ch}=1.6 \mathrm{MW}$

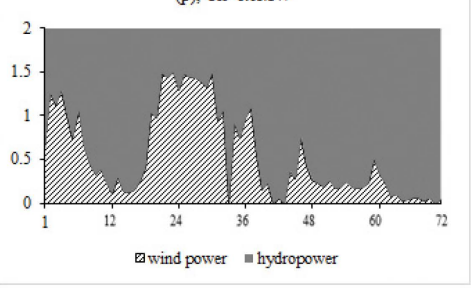

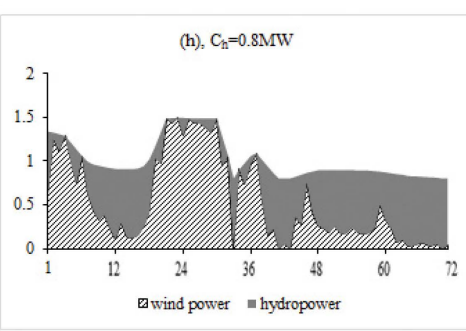

(k), $\mathrm{C}_{\mathrm{h}}=1.1 \mathrm{MW}$

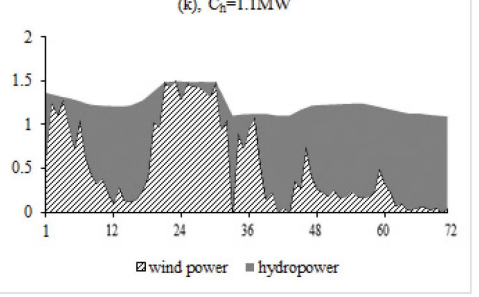

(n), $C_{\mathrm{n}}=1.4 \mathrm{MW}$

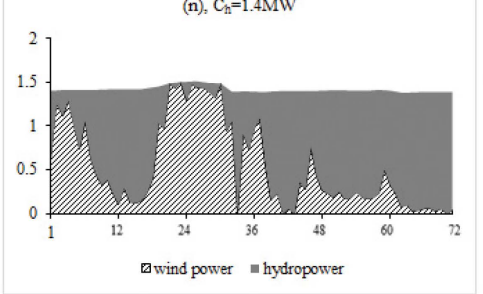

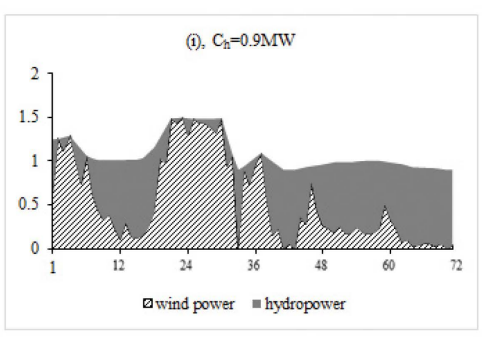

(1), $\mathrm{C}_{\mathrm{n}}=1.2 \mathrm{MW}$

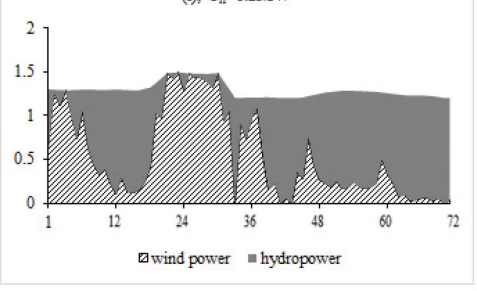

(o), $\mathrm{C}_{\mathrm{h}}=1.5 \mathrm{MW}$

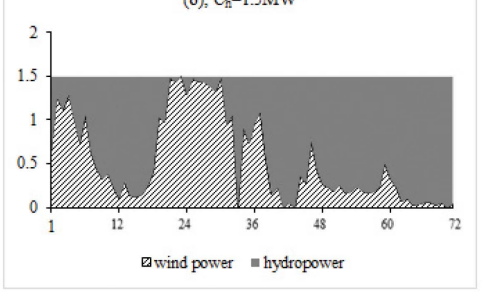

Figure 14. Combined output with different hydropower capacities in flood season. (a) the combined output with hydropower capacities of $0.1 \mathrm{MW}$; (b) the combined output with hydropower capacities of $0.2 \mathrm{MW} ; . . . ;(\mathbf{p})$ the combined output with hydropower capacities of 1.6 MW.

\section{Conclusions}

Indices describing process fluctuations have applications in many fields, especially in evaluating the ability of hydropower to compensate for the intermittency of wind power output. These indices are classified as quantitative or contour. In this investigation, a case study was performed, illustrating that the presently used indices cannot detect the fluctuations of special processes (zigzag and sine/cosine processes) or of processes with different zooms or numbers of repetitions. A new index that employs the $\mathrm{SD}$ and rotation angle was proposed herein to quantify fluctuations. The suggested index was tested by applying it to diverse processes and using various disposals. With disposal of moving average, repeating and overlaying, the new index was found to characterize the fluctuations comparably to the FOD, SD, and RBF indices. With zooming disposal, the new index exhibited a superior ability to reflect the fluctuation characteristics by taking both quantitative and contour variations into consideration. This index was then applied to quantify the fluctuation of a hydro-wind system. The results corresponded to the expected combined output fluctuations in various situations. This research indicates that when compared with the FOD, SD, and RBF indices, the MWF index proposed in this paper can better quantify process fluctuations. The index presented in this paper provides a new method to characterize the output fluctuations of hydro-wind system. In future research, this fluctuation index will be applied to analyze more complex power system and more diverse processes. 
Acknowledgments: This work is supported by the Program of the National Natural Science Foundation of China (51479140) and the Major Program of the National Natural Science Foundation of China (51239004).

Author Contributions: Yadong Mei and Xianxun Wang conceived and designed the experiments; Xiangyu Cong contributed the materials; Hao Cai analyzed the data; Xianxun Wang carried out the main research tasks and wrote the paper; Yadong Mei supervised and checked the whole research.

Conflicts of Interest: The authors declare no conflict of interest.

\section{References}

1. Ackermann, T. Wind Power in Power Systems, 2nd ed.; John Wiley: Chichester, UK, 2012.

2. Sundararagavan, S.; Baker, E. Evaluating energy storage technologies for wind power integration. Sol. Energy 2012, 86, 2707-2717. [CrossRef]

3. Craig, A.; Howard, R.I. Wind Power and Hydropower Integration: Concepts, Considerations and Case Studies; Nova Science Publishers Inc.: Hauppauge, NY, USA, 2012.

4. Acker, T.; Robitaille, A.; Holttinen, H.; Piekutowski, M.; Tande, J. Integration of wind and hydropower systems: Results of IEA wind task 24. Wind Eng. 2012, 36, 1-18. [CrossRef]

5. Bevelhimer, M.S.; McManamay, R.A.; O'Connor, B. Characterizing sub-daily flow regimes: Implications of hydrologic resolution on ecohydrology studies. River Res. Appl. 2014, 31, 867-879. [CrossRef]

6. Wells, M.T. Environmental statistics with S-Plus. J. Am. Stat. Assoc. 2001, 43, 1137-1148. [CrossRef]

7. Anderson, D.R.; Sweeney, D.J.; Williams, T.A. Essentials of Statistics for Business and Economics, 6th ed.; South-Western College: Cincinnati, OH, USA, 2011.

8. Cassola, F.; Burlando, M.; Antonelli, M.; Ratto, C.F. Optimization of the regional spatial distribution of wind power plants to minimize the variability of wind energy input into power supply systems. J. Appl. Meteorol. Climatol. 2008, 47, 3099-3116. [CrossRef]

9. Li, J.; Qiao, Y.; Lu, Z.; Li, J. An evaluation index system for wind power statistical characteristics in multiple spatial and temporal scales and its application. Proc. CSEE 2013, 33, 53-61.

10. Yang, X.; Wang, W.; Xue, B.; Huang, Q. On short-term united optimal operation of wind power, thermal power and waterpower. J. Hydroelectr. Eng. 2013, 32, 199-203.

11. Wang, K.; Luo, X.; Wu, L.; Liu, X. Optimal dispatch of wind-hydro-thermal power system with priority given to clean energy. Proc. CSEE 2013, 13, 27-35.

12. Hoff, T.E.; Perez, R. Quantifying PV power output variability. Sol. Energy 2010, 84, 1782-1793. [CrossRef]

13. Holttinen, H. Hourly wind power variations in the Nordic countries. Wind Energy 2005, 8, 173-195. [CrossRef]

14. Holttinen, H. Impact of hourly wind power variations on the system operation in the Nordic countries. Wind Energy 2005, 8, 197-218. [CrossRef]

15. Richter, B.D.; Baumgartner, J.V.; Wigington, R.; Braun, D.P. How much water does a river need? Freshw. Biol. 1997, 37, 231-249. [CrossRef]

16. Wang, X.L.; Li, Z.W. Multi-objective optimization of combined operation of power station with wind power and pumped water power storage. J. Lanzhou Univ. Technol. 2011, 37, 78-82.

17. Marcos, J.; de la Parra, Í.; García, M.; Marroyo, L.; Marroyo, L. Control strategies to smooth short-term power fluctuations in large photovoltaic plants using battery storage systems. Energies 2014, 7, 6593-6619. [CrossRef]

18. McKinney, T.; Speas, D.W.; Rogers, R.S.; Persons, W.R. Rainbow trout in a regulated river below Glen Canyon Dam, Arizona, following increased minimum flows and reduced discharge variability. N. Am. J. Fish. Manag. 2001, 21, 216-222. [CrossRef]

19. Haas, N.A.; O'Connor, B.L.; Hayse, J.W.; Bevelhimer, M.S.; Endreny, T.A. Analysis of daily peaking and run-of-river operations with flow variability metrics, considering subdaily to seasonal time scales. J. Am. Water Resour. Assoc. 2014, 50, 1622-1640. [CrossRef]

20. Paatero, J.V.; Lund, P.D. Effect of energy storage on variations in wind power. Wind Energy 2005, 8, 421-441. [CrossRef]

21. Haas, J.; Olivares, M.A.; Palma-Behnke, R. Grid-wide subdaily hydrologic alteration under massive wind power penetration in Chile. J. Environ. Manag. 2015, 154, 183-189. [CrossRef] [PubMed]

22. Zimmerman, J.K.; Letcher, B.H.; Nislow, K.H.; Lutz, K.A.; Magilligan, F.J. Determining the effects of dams on subdaily variation in river flows at a whole-basin scale. River Res. Appl. 2010, 26, 1246-1260. [CrossRef] 
23. Violin, C.R.; Cada, P.; Sudduth, E.B.; Hassett, B.A.; Penrose, D.L.; Bernhardt, E.S. Effects of urbanization and urban stream restoration on the physical and biological structure of stream ecosystems. Ecol. Appl. 2011, 21, 1932-1949. [CrossRef] [PubMed]

24. Kern, J.D.; Patino-Echeverri, D.; Characklis, G.W. The impacts of wind power integration on sub-daily variation in river flows downstream of hydroelectric dams. Environ. Sci. Technol. 2014, 48, 9844-9851. [CrossRef] [PubMed]

25. Richter, B.D.; Baumgartner, J.V.; Powell, J.; Braun, D.P. A method for assessing hydrologic alteration within ecosystems. Conserv. Biol. 1996, 10, 1163-1174. [CrossRef]

26. Gustafson, D.I.; Carr, K.H.; Green, T.R.; Christophe, G.; Jones, R.L.; Peter, R. Fractal-based scaling and scale-invariant dispersion of peak concentrations of crop protection chemicals in rivers. Environ. Sci. Technol. 2004, 38, 2995-3003. [CrossRef] [PubMed]

27. Baker, D.B.; Richards, R.P.; Loftus, T.T.; Kramer, J.W. A new flashiness index: characteristics and applications to Midwestern rivers and streams. J. Am. Water Resour. Assoc. 2004, 40, 503-522. [CrossRef]

28. Zhang, Z.; Zhou, Q.; Kusiak, A. Optimization of wind power and its variability with a computational intelligence approach. IEEE Trans. Sustain. Energy 2014, 5, 228-236. [CrossRef]

29. Sauterleute, J.F.; Charmasson, J. A computational tool for the characterisation of rapid fluctuations in flow and stage in rivers caused by hydropeaking. Environ. Model. Softw. 2014, 55, 266-278. [CrossRef]

30. Wang, X.X.; Mei, Y.D.; Duan, W.H.; Yang, N. Optimal Operation Models of Pumped Storage Power Station. Hydropower Autom. Dam Monit. 2008, 32, 1-3.

31. Wang, X.X. Optimization of Operation of Pumped Storage Station; Wuhan University: Wuhan, China, 2008.

32. Zhao, L.; Li, Y.Q. An Optimal Operation Scheduling Method of Pumped Storage Station Based on Load Curve Quantification. Mod. Electr. Power 2014, 31, 51-54.

33. Wang, X.X.; Mei, Y.D. A Method and System of Stability Analysis of Power Station Operation Based on Process of Output. China Patent CN103605907A, 26 February 2014.

34. Ge, H.; Guo, Q.; Sun, H.; Wang, B.; Zhang, B.; Wu, W. A load fluctuation characteristic index and its application to pilot node selection. Energies 2014, 7, 115-129. [CrossRef]

35. The Nature Conservancy. Indicators of Hydrologic Alteration; Version 7, User's manual; The Nature Conservancy: Arlington, VA, USA, 2007.

36. MERRA: Modern-era Retrospective Analysis for Research and Applications. Available online: https://gmao.gsfc.nasa.gov/research/merra/ (accessed on 17 February 2016). 